\title{
Coping as a Personality Process: A Prospective Study
}

\author{
Niall Bolger \\ University of Denver
}

\begin{abstract}
The study tested the proposition that coping is personality in action under stress. Using a stressful medical school entrance examination, the study examined (a) whether neuroticism emerged in coping patterns over time and (b) whether the influence of neuroticism on coping accounted for changes in anxiety and examination performance. Fifty premedical students reported their coping efforts at 35 days before, 10 days before, and 17 days after the examination. They provided daily reports of anxiety for 35 days surrounding the examination. Neuroticism influenced coping efforts and increases in daily anxiety under stress. Two types of coping, wishful thinking and self-blame, explained over half the relationship between neuroticism and increases in preexamination anxiety. Consistent with previous research, neither neuroticism nor specific coping efforts influenced examination performance.
\end{abstract}

Under stress, some people become distressed or perform poorly, whereas others remain resilient. Coping theorists assume that these outcomes result from people's coping efforts to alter the stressful situation or to regulate their emotional reactions (Lazarus \& Folkman, 1984). Coping, thus, is a process explanation for differences in stress outcomes. Personality dispositions also may explain why some people are vulnerable to stress but others are not. For example, trait theories of personality view neuroticism as individual differences in emotional reactivity to stress (Costa \& McCrae, 1985; Eysenck \& Eysenck, 1985). If both personality dispositions and coping processes can explain individual differences in stress outcomes, then how do these explanations fit together? In this study I tested whether coping processes mediated the effects of neuroticism on psychological distress and performance under stress.

I tested this proposition by investigating how premedical students coped with a major stressful event, a medical school entrance examination. In doing so, I sought to forge a link between a trait orientation to personality, represented by neuroticism, and a process orientation to personality, represented by individual differences in patterns of coping over time.

\section{Neuroticism, Coping, and Anxiety}

Anxiety is perhaps the most characteristic emotion experienced in stressful situations (i.e, situations that tax or exceed the person's available resources). Yet, not everyone exposed to the same stressful situation becomes equally anxious. To explain individual differences in anxiety under stress, it is useful to distinguish trait and state anxiety. Trait anxiety is the disposition to show anxiety across diverse situations. State anxiety, in

I am grateful to Jane Crawford and Don Cook for access to the sample, to Paula Hanpeter and Stuart Beraha for research assistance, and to Daryl Bem, Steven Cornelius, James Coyne, Geraldine Downey, Abby Stewart, Camille Wortman, and three anonymous reviewers for comments on earlier drafts of the article.

Correspondence concerning this article should be addressed to Niall Bolger, Department of Psychology, University of Denver, Denver, Colorado 80208. contrast, is the anxiety people experience on a moment-by-moment basis. The state-trait theory of anxiety proposes that people who are high on trait anxiety will show the greatest increases in state anxiety under stress (Endler \& Edwards, 1982; Eysenck \& Eysenck, 1985; Spielberger, Gorsuch, \& Lushene, 1970).

Watson and Clark (1984) presented compelling evidence that neuroticism and trait anxiety represent the same underlying disposition, which they termed negative affectivity. In this study, therefore, I treated neuroticism and trait anxiety as equivalent concepts. Consequently, as predicted by the state-trait theory of anxiety, I expected that individuals high on neuroticism would be most vulnerable to increases in anxiety under stress.

What specific coping processes mediate the relationship between neuroticism and increases in anxiety under stress? Researchers often distinguish two major types of coping efforts, problem-focused and emotion-focused coping. More detailed taxonomies also exist. Marshall and Dunkel-Schetter (1987) reviewed factor-analytic studies of the most widely used coping measure, the Ways of Coping Inventory (Folkman \& Lazarus, 1980). These authors identified six main types of coping: (a) problem-focused coping, (b) seeking support, (c) focusing on the positive (i.e, reappraising the situation in a positive way), (d) distancing (i.e, minimizing threat by becoming psychologically detached from the stressful situation), (e) wishful thinking (i.e., engaging in fantasies about escaping or avoiding the situation), and (f) self-blame.

Wishful thinking and self-blame appear to be particularly characteristic of people high in neuroticism (McCrae \& Costa, 1986). Cross-sectional studies have shown that these ways of coping predict distress (Felton, Revenson, \& Hinrichsen, 1984; Folkman \& Lazarus, 1985). For wishful thinking, researchers have also found this relationship in a prospective study that controlled for initial level of distress (Felton \& Revenson, 1984). This finding shows that wishful thinking is not merely a proxy for distress itself and supports the proposition that certain types of ineffective coping may explain why people high in neuroticism are reactive to stress. 
McCrae and Costa (1986), however, failed to confirm this proposition. In a community sample, both neuroticism and coping related to distress, but coping did not explain the relationship of neuroticism to distress. Rather, the coping-distress relationship was spurious: Coping showed no relationship to distress when neuroticism was statistically controlled. McCrae and Costa therefore claimed that people's reports of their coping efforts are "epiphenomena of personal ity" and have no independent causal status. This claim challenges the belief that coping has a causal influence on stress outcomes, a central assumption of coping theories.

The coping-distress relationships found by McCrae and Costa (1986) may have been misleading. Subjects were given the difficult task of recalling how they had coped with a target event that had happened up to 21 months previously. For subjects' coping efforts to explain their emotional reactions to this stressful event, it is imperative that they accurately recall how they coped with the stressful event in question. Rather than recalling the specific coping strategies they used to deal with that stressful event, subjects may have reported how they typically cope with stress. There is evidence that as time elapses, people become more biased toward dispositional accounts of their own behavior (Moore, Sherrod, Liv, \& Underwood, 1979; Peterson, 1980). The operation of this bias in the McCrae and Costa study could explain why subjects' coping reports had no independent relationship to distress when neuroticism, a superordinate personality measure that encompasses dispositional coping, was controlled. In the current study, therefore, I reexamined the relationship among neuroticism, coping, and distress using concurrent reports of coping with a specific stressor.

\section{Neuroticism, Coping, and Performance in Stressful Situations}

Besides affecting psychological distress, stress also can affect people's performance in a stressful situation. Under stress, people high in neuroticism experience emotions and cognitions that distract them from the task at hand (Watson \& Clark, 1984). Yet this distraction does not impair their performance (Eysenck \& Eysenck, 1985). Eysenck (1983) has argued that people high in neuroticism compensate for their distress by increasing their task-oriented efforts (e.g, problem-focused coping). Compensation also may occur through other modes such as distancing and seeking support.

This compensation model implies that one should observe two mediational effects of opposite sign: Coping efforts that increase anxiety (e.g, wishful thinking) should impair performance, and compensatory coping efforts (e.g., problem-focused coping) should improve performance. Because the compensation model has been tested only in laboratory situations, it is unclear whether it generalizes to naturalistic stressors. In the current study I investigated whether the compensation process operates when people confront a significant real-life stressor.

\section{Methodological Problems in Research on Personality and Coping}

Several problems limit the contributions of previous correlational research on personality-coping relationships. First, many studies that show a link between personality and coping assume that coping can explain the link between personality and stress outcomes (e.g., Fleischman, 1984; Holohan \& Moos, 1987; Parkes, 1984, 1986; Scheier, Weintraub, \& Carver, 1986). Except for the McCrae and Costa (1986) study, this assumption remains untested.

Second, most studies have been cross-sectional, leaving issues of causal directionality unresolved. In such studies it is often plausible that stress outcomes can affect levels of coping. For example, cross-sectional correlations between wishful thinking and distress might reflect the effects of distress on wishful thinking, rather than the reverse. Unfortunately, with cross-sectional data it is almost impossible to determine the extent to which observed coping-outcome correlations are generated through stress outcomes affecting levels of coping.

Third, existing studies rarely view coping as a process that unfolds over time (Lazarus \& Folkman, 1984; Pearlin, Lieberman, Menaghan, \& Mullan, 1981). Yet interactional perspectives on personality - such as the state-trait theory of anxietyimply that personality effects emerge only at certain times in the coping process. Thus, it is important to simultaneously examine whether and when personality matters for coping.

Fourth, many studies of personality and coping use aggregated or heterogeneous measures of stressful events (e.g., McCrae \& Costa, 1986; Parkes, 1984). These types of measures do not permit one to rule out the possibility that differences in people's coping strategies reflect differences in the types of stressors they experience.

Finally, most research examines how coping affects mental health, and conventional coping measures have been validated by their ability to predict distress (Kessler, Price, \& Wortman, 1985). Researchers need to consider other outcomes such as performance under stress (Baum, Grunberg, \& Singer, 1982). It is unclear whether conventional coping measures are wellsuited to this task.

\section{The Present Study}

The goals of the study were (a) to examine the emergence of a major personality disposition, neuroticism, in patterns of coping over time; and (b) to test whether coping mediated the influence of neuroticism on psychological distress and on performance under stress.

To meet these goals, I designed a prospective study of individuals experiencing a homogeneous stressful event. The event is one of the most stressful examinations on a college campus, the Medical College Admissions Test (MCAT). Most medical school applicants take this day-long examination, and their test scores weigh heavily in medical school admission decisions.

Scheduled events such as examinations have several features that make them attractive for achieving the goals of this study. First, individual-difference variables such as neuroticism can be measured before the event. In the present study, I measured neuroticism 5 weeks before the MCAT examination.

Second, potential mediating variables such as coping efforts can be obtained at various times before and after the event, allowing the investigator to examine mediational processes over time. I measured coping at three points in time: 5 weeks before the examination, a time of moderately high stress; 10 


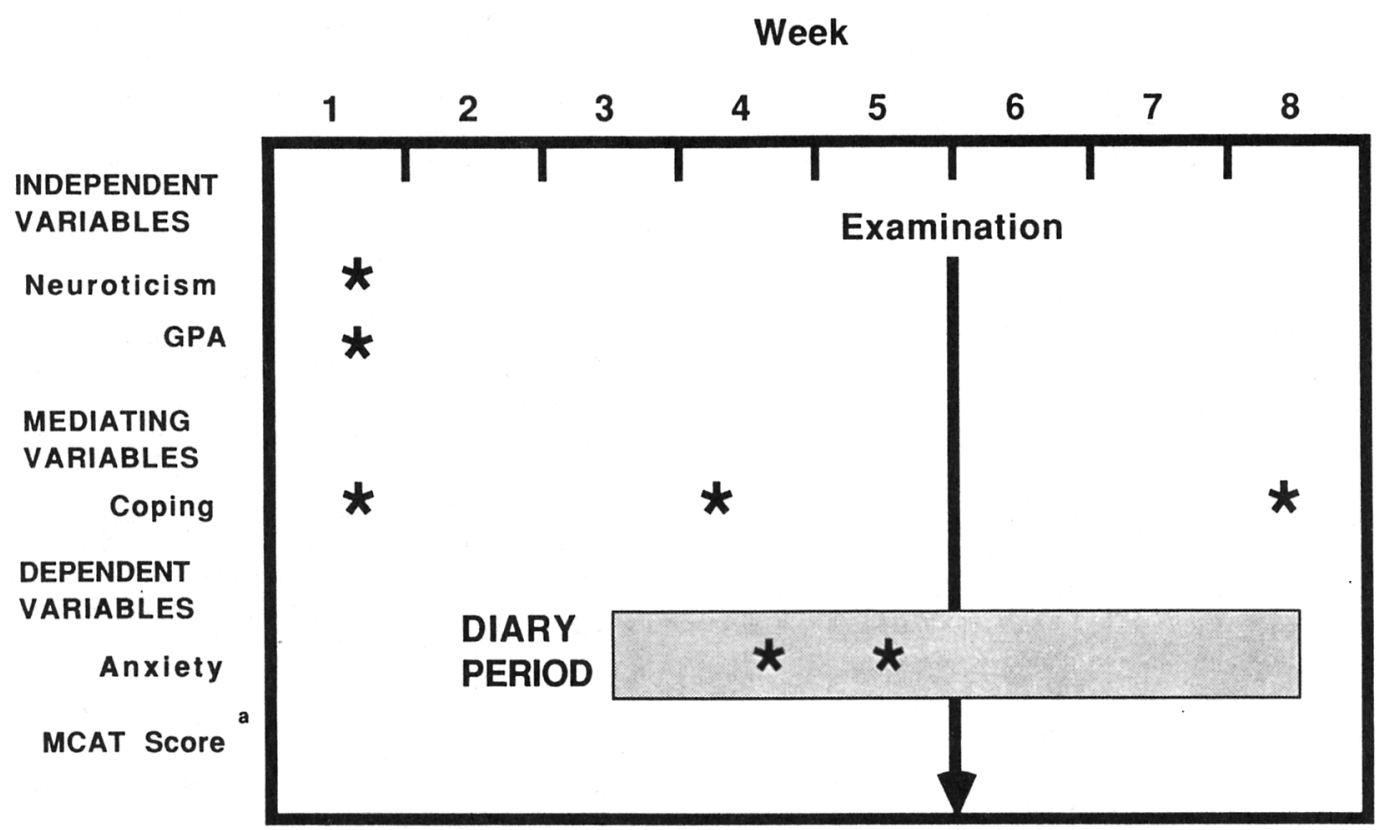

Figure 1. MCAT study design. (GPA = grade point average; $\mathrm{MCAT}=$ Medical College Admissions Test. ${ }^{2}$ Obtained 6 weeks after the examination.)

days before the examination, a time of high stress; and 2.5 weeks after the examination (but 1 month before the results became available), a time of low stress. I expected that neuroticism would have the largest effect on coping patterns during the preexamination period.

Third, measures of psychological distress and performance indicators (i.e, examination scores) are readily available. I obtained measures of anxiety each day for the 35-day period surrounding the examination, and I obtained self-reports of MCAT scores following the examination.

Previous researchers have also used college examinations to test general theories of stress and coping. Examples include Mechanic's (1962) classic study of a graduate school preliminary examination and recent work by Folkman and Lazarus (1985) on an undergraduate midterm examination. Both studies used the scheduled nature of examinations to obtain repeated measurements of stress-process variables. Neither, however, focused on the effects of personality traits on coping and stress outcomes. ${ }^{1}$

In sum, this study investigated the interrelationships of personality, coping, and stress outcomes during a major stressful event among college students, a medical school entrance examination. The study tested whether neuroticism emerged in patterns of coping in the weeks surrounding the event and whether coping mediated the influence of neuroticism on changes in distress and examination performance.

\section{Method}

\section{Design and Sample}

Figure 1 presents an overview of the study design. Measures of personality (neuroticism) and prior academic performance (grade point average [GPA]) were obtained in an initial questionnaire, completed 35 days before the examination. Measures of coping modes were obtained at three time points: twice before (at 35 days and 10 days) and once after (17 days) the examination. Psychological outcomes (anxiety scores) were measured daily in the 5-week period surrounding the examination. Performance outcomes (MCAT scores) were obtained when they became available to students, at 6 weeks after the examination.

Subjects were recruited at a registration session for the MCAT at a major university. Recruitment took place approximately 9 weeks before the examination. Two hundred and twenty-six students registered for the MCAT. As students left the registration hall, they were given a handout inviting them to take part in a study of examination stress. For their participation, subjects were offered $\$ 20$ and feedback on the results of the study. Because the flow of students through the hall was very swift, only 106 students were given handouts. Of these, 84 indicated that they were interested in learning more about the study.

Four weeks later ( 5 weeks before the examination) interested persons were mailed $\$ 5$ in cash and an initial (Time 1 [T1]) questionnaire that assessed personality and current methods of coping with the examination. I chose this time point on the assumption that it represented a period of moderately high stress. Sixty-eight persons agreed to participate in the study and completed the Time 1 questionnaire.

Seventeen days before the examination, subjects received the first of five booklets of structured daily diaries (self-report questionnaires) together with an additional $\$ 5$ in payment. Each booklet contained seven daily diaries. The diaries measured changes in psychological distress during the weeks surrounding the examination (see Measures section). Diaries were completed daily at bedtime, and this task usually

\footnotetext{
${ }^{1}$ For those interested in work on personality and examination outcomes that views personality from a goal-oriented, strategic perspective rather than from an interactional state-trait perspective (the approach taken here), see the excellent work of Cantor, Norem, and their associates (Cantor, Norem, Niedenthal, Langston, \& Brower, 1987; Norem \& Cantor, 1986a, 1986b).
} 
took less than $2 \mathrm{~min}$. Subjects received additional booklets each week and returned the booklets by mail weekly. On completion of the diary phase of the study, each subject received a final $\$ 10$ payment. Fifty-one subjects returned all five diary booklets, and 60 subjects completed diaries up to and including the examination day.

Ten days before the examination, a time that I assumed to be highly stressful, subjects provided Time 2 (T2) measures of coping. Seventeen days after the examination (but 1 month before receiving the results) subjects provided a further (Time 3 [T3]) set of coping responses. I assumed this was a time of low stress. Fifty subjects provided complete data at all three time points.

Subjects received their examination scores approximately 6 weeks after the examination. They then received a final questionnaire requesting them to report these scores. Fifty subjects did so.

This final sample $(N=50)$ comprised 24 men and 26 women; the average age was 20.3 years $(S D=.8)$. Comparisons of the original and final samples on age, sex, and GPA showed there was no significant sample attrition during the study (Bolger, 1987). Other descriptive statistics based on the final sample are presented below.

Although 226 students registered for the MCAT, only 160 took the exam. Thus, approximately one third of those who took the MCAT were enrolled in the present study. For both GPA and MCAT score, the final sample mean $(N=50)$ closely approximated that of the population of students who took the test. In the case of GPA, a test of the hypothesis that the sample $(M=3.40, S D=0.30)$ was randomly drawn from the population $(M=3.37, S D=0.38)$ was nonsignificant $(z=$ $0.56, n s)$. For MCAT score, a test of the hypothesis that the sample $(M=$ $63.0, S D=7.5)$ was randomly drawn from the population $(M=62.1$, $S D=8.3$ ) was also nonsignificant $(z=0.77)$ ( $(\mathrm{see}$ Measures section below for more details on MCAT scores). These results suggest that the study sample was unbiased with respect to prior academic performance and performance on the MCAT.

\section{Measures}

Neuroticism. In the $\mathrm{Tl}$ questionnaire, each subject completed a 24item neuroticism scale (Form B) from the Eysenck Personality Inventory (Eysenck \& Eysenck, 1964). Items include "Would you call yourself a nervous person?" and "Are you an easy-gaing person, not generally bothered about having everything 'just so"?" The mean and standard deviation, based on $N=50$, were 12.2 and 4.6 units. Eysenck and Eysenck (1964) reported that a normative sample of 239 U.S. college students had a neuroticism mean and standard deviation of 11.1 and 4.8 units. Neither the mean nor the standard deviation of the Eysenck sample differed significantly from the current sample mean and standard deviation: mean difference, $t(287)=0.94, n s$; standard deviation difference, $F(238,49)=1.13, n s)$.

Coping. This was measured using the Ways of Coping Scale (Folkman \& Lazarus, 1980,1985). At the two time points before the examination, subjects read the following introductory passage: "Thinking of the forthcoming MCAT examination, please indicate below whether you are currently using any of the following ways of responding or thinking about it." At the time point following the examination (T3) the introduction was modified to "Thinking of the MCAT examination just passed, please indicate. . ." Responses to each coping item were recorded using a yes-no checklist format.

Using data from a study of examination stress, Folkman and Lazarus (1985) identified eight subscales of the Ways of Coping Scale. In the present study only six of these eight subscales were reliable enough (Cronbach's $\alpha>.5$ ) for use in analyses: (a) problem-focused coping (10 items; $\alpha=.77$ ), (b) seek support (7 items; $\alpha=.70$ ), (c) wishful thinking (5 items; $\alpha=.67$ ), (d) self-blame ( 3 items; $\alpha=.63$ ), (e) distancing (5 items; $\alpha=.57$ ), and (f) focus on the positive ( 4 items; $\alpha=.58$ ). These same six scales have emerged consistently in previous factor-analytic studies of the Ways of Coping Scale (Marshall \& Dunkel-Schetter, 1987).

Scores on each coping scale were expressed as percentages of the maximum possible score. For example, a score of $\mathbf{4 0}$ indicates that a subject checked $40 \%$ of the items on a particular scale. Percentage scores allow easy comparisons over time and across coping scales (e.g., How much were individuals engaging in problem-focused coping compared with wishful thinking?).

Anxiety. The daily diary instrument contained three items from the Profile of Mood States (Lorr \& McNair, 1971): (a) "on edge," (b) "uneasy", and (c) "nervous." These items were the three highest loading items on an anxiety factor obtained in a validation study with college students (see Lorr \& McNair, 1971, p. 26). In the present study respondents rated each item on the extent to which they had experienced the particular emotion during the previous $24 \mathrm{hr}$. The following 5-point scale was used: $1=$ not at all, $2=$ a little, $3=$ moderately, $4=$ quite $a$ bit. $5=$ extremely. Anxiety scores (obtained by summing the item scores) ranged from 3 to 15 . Based on pooled data across all diary days, the Cronbach alpha of the scale was 87 .

Examination score. The MCAT is composed of six subtests, each with a theoretical range of 0 to 15 units. Therefore, total MCAT scores can range from 0 to 90 . The sample mean $(N=50)$ was 63 and the standard deviation was 7.5 .

\section{Results}

\section{Overview}

The Results section describes two major sets of analyses. This first set determines whether coping explains the relationship between neuroticism and changes in anxiety under stress. The second set determines whether coping explains the relationship between neuroticism and examination score, controlling for GPA.

Several conditions must be met to show that coping explains the relationship between neuroticism and anxiety increases under stress. First, it is necessary to show that neuroticism predicts coping under stress. Second, it is necessary to show that anxiety increases under stress and that neuroticism predicts who becomes most differentially anxious. Finally, it is necessary to show that the relationship between neuroticism and anxiety increases is substantially reduced when coping is statistically controlled. The following section addresses the first of these questions.

\section{Effects of Neuroticism on Coping}

To examine temporal changes in the impact of neuroticism on coping, the sample was divided into low (scores $3-8 ; 22 \%$ of the sample, $n=11)$, medium $(9-15 ; 56 \%, n=28)$, and high $(16-22 ; 22 \%, n=11)$ neuroticism groups. Then a $3 \times 3$ (Neuroticism $\times$ Time) repeated measures analysis of variance (ANOVA) with time as the repeated measures factor was conducted. Trichotomizing neuroticism was intended to facilitate the use of a repeated-measures analysis and to permit the comparison of students with typical levels of neuroticism with those with more extreme levels. I performed the repeated-measures ANOVA in the multivariate mode (analyzing all six coping scales to- 
Table 1

Patterns of Coping as a Function of Neuroticism: Time-Invariant and Time-Varying Effects

\begin{tabular}{|c|c|c|c|c|c|}
\hline \multirow[b]{3}{*}{ Coping } & \multirow{2}{*}{\multicolumn{3}{|c|}{ Neuroticism }} & \multicolumn{2}{|c|}{ Planned comparisons } \\
\hline & & & & \multirow{2}{*}{$\begin{array}{c}\text { Low vs. high } \\
\text { neuroticism } \\
F(1,47)\end{array}$} & \multirow{2}{*}{$\begin{array}{c}\text { Neuroticism } \\
\text { (low vs. high) } \times \\
\text { Time }(1 \& 2 \text { vs. } 3) \\
F(1,94)\end{array}$} \\
\hline & $\begin{array}{c}\text { Low } \\
(n=11)\end{array}$ & $\underset{(n=38)}{\text { Medium }}$ & $\begin{array}{c}\text { High } \\
(n=11)\end{array}$ & & \\
\hline Problem focused & 33 & 27 & 27 & 1.01 & 2.85 \\
\hline Focus on the positive & 36 & 23 & 30 & 0.60 & 0.19 \\
\hline Seek support & 33 & 23 & 36 & 0.08 & 0.33 \\
\hline Distancing & 26 & 31 & 40 & $5.88^{*}$ & 0.29 \\
\hline Wishful thinking & 23 & 30 & 53 & $13.38^{* *}$ & $4.14^{*}$ \\
\hline Self-blame & 15 & 23 & 35 & $6.71^{*}$ & $16.04^{* *}$ \\
\hline
\end{tabular}

Note. Scores on each coping scale are expressed as percentages of the total possible score.

$* p<.05$. $^{* *} p<.001$.

gether) and, where significant effects emerged, I performed supplementary univariate analyses (analyzing each coping scale separately; see Bock, 1975).

In the repeated-measures analysis, tests of Neuroticism $\times$ Time interactions were of most theoretical interest: These tests assess whether neuroticism is differentially expressed in coping in times of high stress. I will present these results first. Then I will present main effects of neuroticism that are unqualified by time and main effects of time that are unqualified by neuroticism.

Neuroticism $\times$ Time interactions. Because I hypothesized that the effects of neuroticism on coping would be greatest in times of high stress, I carried out the following planned comparisons (expressed as focused, one-degree-of-freedom tests; see Rosenthal \& Rosnow, 1985). I tested whether the influence of neuroticism (low vs. high) on coping was strongest at the two preexamination time points ( $\mathrm{T} 1$ and $\mathrm{T} 2$ vs. $\mathrm{T} 3$ ), and presumably, the most stressful conditions. The multivariate test of this effect was significant, Wilks's lambda $=.792, F(1,94)=3.90$, $p<.002$, two-tailed (all subsequent tests are two-tailed).

Table 1, column 5 , presents the results of the equivalent univariate planned comparisons. Two coping scales showed the expected pattern: wishful thinking and self-blame.

Figure 2 gives the means for wishful thinking. Three post hoc tests were performed. The tests compared the means for the high- and low-neuroticism groups at each time point. The Bonferroni correction procedure for multiple comparisons was used to keep the overall alpha level at .05 . Each post hoc test, therefore, needed to be significant at alpha less than $.05 / 3=$ .017 . The Bonferroni correction procedure was used in all subsequent multiple comparisons.

The tests show that neuroticism predicts wishful thinking only during the preexamination period. At both $\mathrm{T} 1$ and $\mathrm{T} 2$, high-neuroticism subjects engaged in significantly more wishful thinking than low-neuroticism subjects: T1, $M_{\text {high }}-M_{\text {low }}=$ $40, F(1,94)=20.87, p<.001 ; \mathrm{T} 2, M_{\text {high }}-M_{\text {low }}=37, F(1,94)=$ $17.60, p<.001$. After the examination, group differences were nonsignificant, $M_{\text {uigh }}-M_{\text {low }}=17, F(1,94)=3.58$, ns.

Figure 3 shows that the pattern for self-blame was highly similar to the pattern for wishful thinking. Compared with those low in neuroticism, high-neuroticism subjects used significantly more self-blame at $\mathrm{T} 1, M_{\text {high }}-M_{\text {low }}=34, F(1,94)=$ $17.69, p<.001$, and at T2, $M_{\text {high }}-M_{\text {low }}=33, F(1,94)=17.00$, $p<.001$. By T3, however, neuroticism no longer predicted the use of self-blame, $M_{\text {high }}-M_{\text {low }}=-6, F(1,94)=0.55$, $n s$.

To summarize, neuroticism predicted individual differences in coping patterns in the weeks around the MCAT examination. For wishful thinking and self-blame, the effect of neuroticism was strongest during the preexamination period, a period of high stress.

Three of the six coping modes-problem-focused coping, seeking support, and distancing-showed unqualified main effects of neuroticism, time, or both. These results are described below.

Main effects of neuroticism. Table 1, columns 1 through 3, shows mean levels of coping averaged across the three time points for low, medium, and high neuroticism groups. Because I expected that the low and high groups would differ on coping, I carried out the appropriate multivariate and univariate planned comparisons.

The multivariate test of group differences across all six coping scales was statistically significant, Wilks's Lambda $=.70$, $F(1,47)=2.99, p<.02$. Equivalent univariate comparisons showed that subjects high in neuroticism engaged in more distancing, more wishful thinking, and more self-blame than those low in neuroticism. Of the three, only the result for distancing is relevant here, because, as shown earlier, the effects of neuroticism on wishful thinking and self-blame are qualified by time.

Main effects of time. Table 2, columns 1 through 3, presents means on each of the six coping scales, averaged across levels of neuroticism, for the three time points- -35 days before, 10 days before, and 17 days after the examination.

Because I expected that situational demands-and therefore, coping efforts-would be greatest in the preexamination period, I used planned comparisons to test whether subjects' levels of coping changed from the pre- to postexamination periods. The hypothesis was confirmed. The multivariate test of the difference between coping at $T 1$ and $T 2$ versus $T 3$ was highly significant, Wilks's Lambda $=.36, F(1,94)=26.22, p<$ 


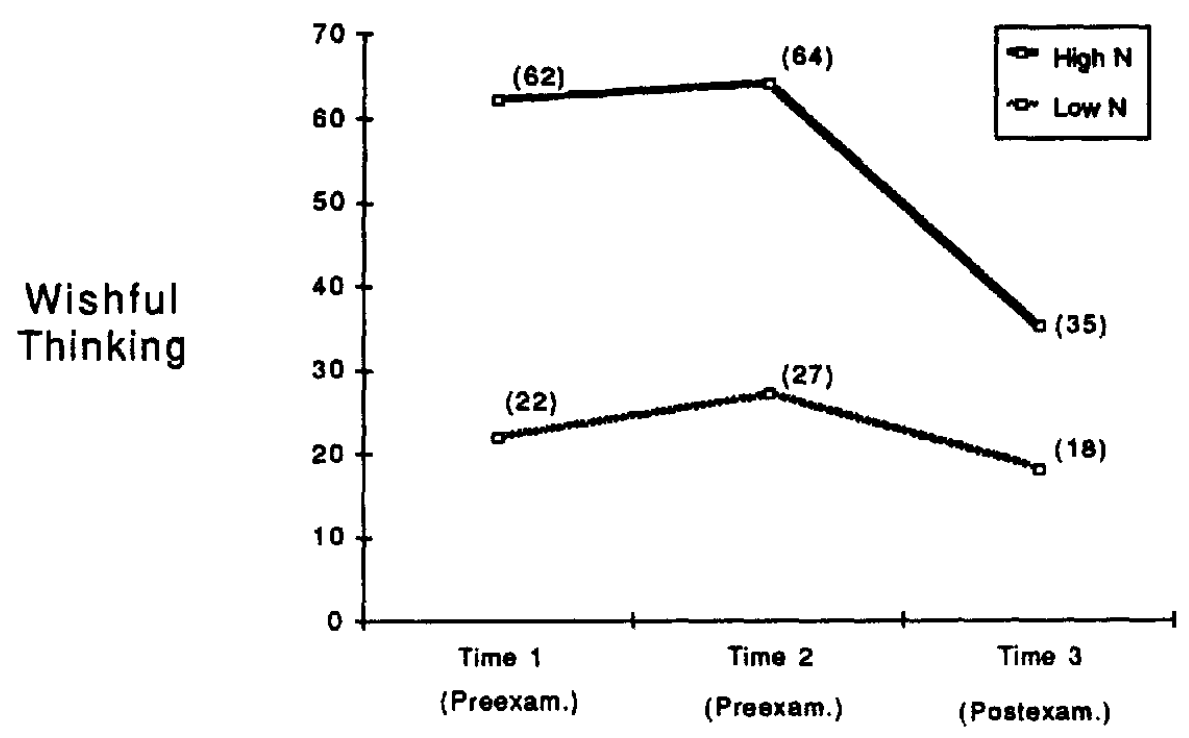

Figure 2. Wishful thinking (percentage scores) as a function of neuroticism (N) and time.

.001 . Univariate planned comparisons showed that preexamination coping differed significantly from postexamination coping for all scales except focusing on the positive. Table 2, column 4, gives the results of these tests.

In summary, although certain coping modes showed Neuroticism $\times$ Time interactions, others showed unqualified main effects of time (i.e, situational effects). Thus, as a group, subjects showed similar patterns of change over time in their use of problem-focused coping, distancing, and seeking support. Certain coping modes also showed cross-situational effects of neuroticism. Thus, subjects high in neuroticism engaged in more distancing at all points in time than subjects low in neuroticism.
Neuroticism, Coping, and Anxiety Increases Under Stress

I have shown that neuroticism predicts the use of certain coping modes under stress. I next turn to the question of whether anxiety increased under stress and whether neuroticism predicts who became most differentially anxious.

Increases in daily anxiety. As the MCAT examination ap proached, subjects showed substantial increases in daily anxiety. Figure 4 shows mean daily anxiety over the 5 -week period surrounding the MCAT examination. To test broad changes in anxiety over this time, I distinguished three time periods: the first 10 days of the diary study (Period 1), the final week before the examination (Period 2: days 11 to 17), and the postexamina-

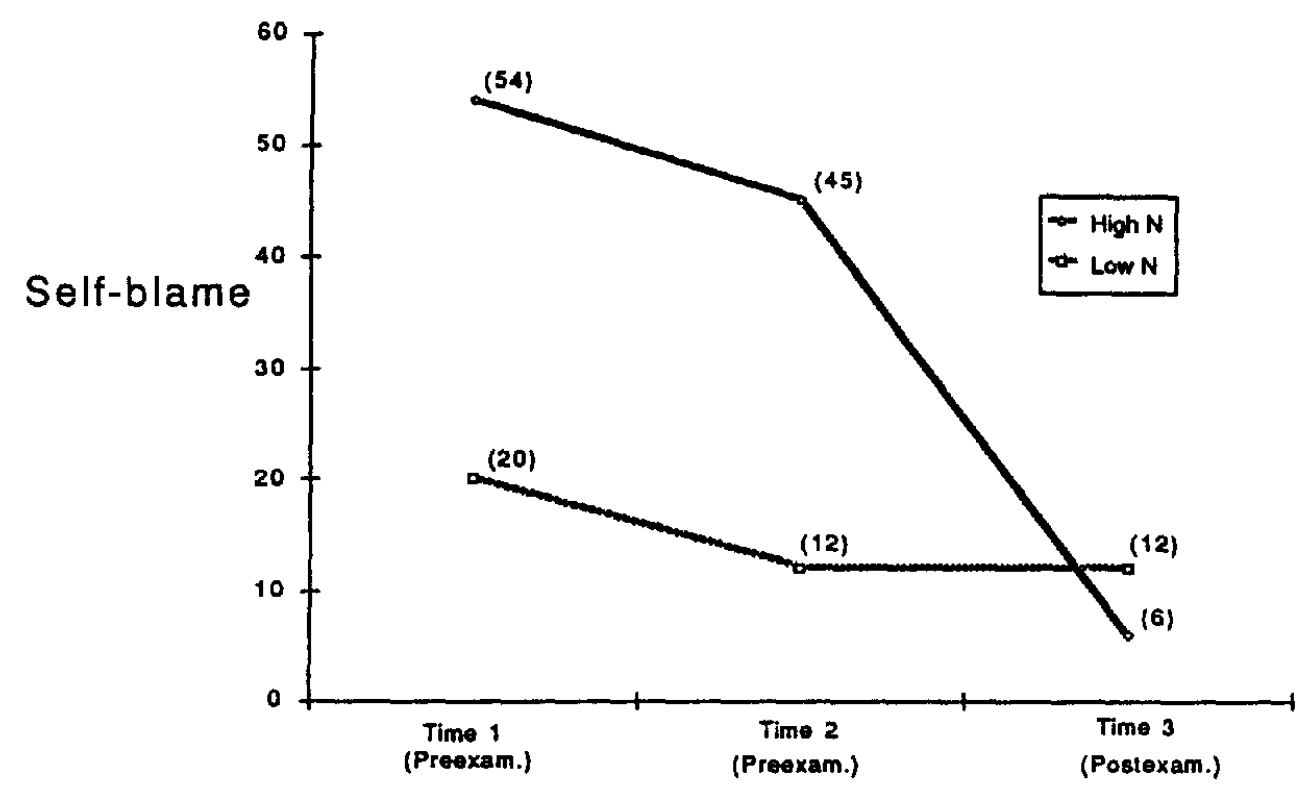

Figure 3. Self-blame (percentage scores) as a function of neuroticism (N) and time. 
Table 2

Patterns of Coping as a Function of Time

\begin{tabular}{|c|c|c|c|c|}
\hline \multirow[b]{2}{*}{ Coping } & \multicolumn{3}{|c|}{ Time } & \multirow{2}{*}{$\begin{array}{c}\text { Planned comparison } \\
\text { Times } 1 \& 2 \\
\text { vs. Time } 3 \\
F(1,94)\end{array}$} \\
\hline & $\stackrel{1}{\text { (Preexamination) }}$ & $\begin{array}{c}2 \\
\text { (Preexamination) }\end{array}$ & $\begin{array}{c}3 \\
\text { (Postexamination) }\end{array}$ & \\
\hline Problem focused & 40 & 31 & 17 & $42.52^{*}$ \\
\hline Focus on the positive & 39 & 24 & 26 & 2.31 \\
\hline Seek support & 37 & 34 & 21 & $21.07^{*}$ \\
\hline Distancing & 26 & 20 & 52 & $56.19^{*}$ \\
\hline Wishful thinking & 40 & 41 & 25 & $16.47 *$ \\
\hline Self-blame & 35 & 30 & 8 & $43.38^{*}$ \\
\hline
\end{tabular}

Note. Scores on each coping scale are expressed as percentages of the total possible score. $N=50$.

$* p<.001$

tion period (Period 3: days 18 to 35 ). The sample size was 51. A one-way repeated measures ANOVA with time as a repeated measures factor was carried out on each person's mean anxiety for each period.

Mean anxiety was noticeably higher in the preexamination period than in the postexamination period. This was particularly true in the final week before the MCAT. The means for Periods 1,2 , and 3 were, respectively, $6.51,7.44$, and 5.58. The three means differed significantly from one another, $F(2$, $100)=7.68, p<.001$, and all pairwise comparisons differed significantly. Thus, mean anxiety was highest in the week before the examination.

Neuroticism and increases in daily anxiety. Did neuroticism predict who became most differentially anxious as the examination approached? To answer this question, I used only those daily measures of anxiety obtained after the $\mathrm{T} 2$ measure of coping but before the examination day. This permitted the estimation of a mediational model linking neuroticism, coping at $\mathrm{Tl}$ and $\mathrm{T} 2$, and anxiety changes following T2 (see Figure 1).

Initial anxiety was defined as the measure for the day following the T2 measure of coping (Day 9 of the diary study). This was 9 days before the examination day. Because Day 9 followed the T2 coping measure, it seemed reasonable to assume that anxiety on this day was more likely to be a consequence than a cause of coping. Also, Day 9 preceded the sharp increase in anxiety in the final week before the examination (shown in Figure 4), making it a suitable index of initial anxiety.

Almost all subjects showed heightened anxiety in the last several days before the examination. There were marked differences, however, in when anxiety peaked. For many subjects, anxiety peaked on the day before the examination; for some, however, peak anxiety occurred as many as 4 days before the

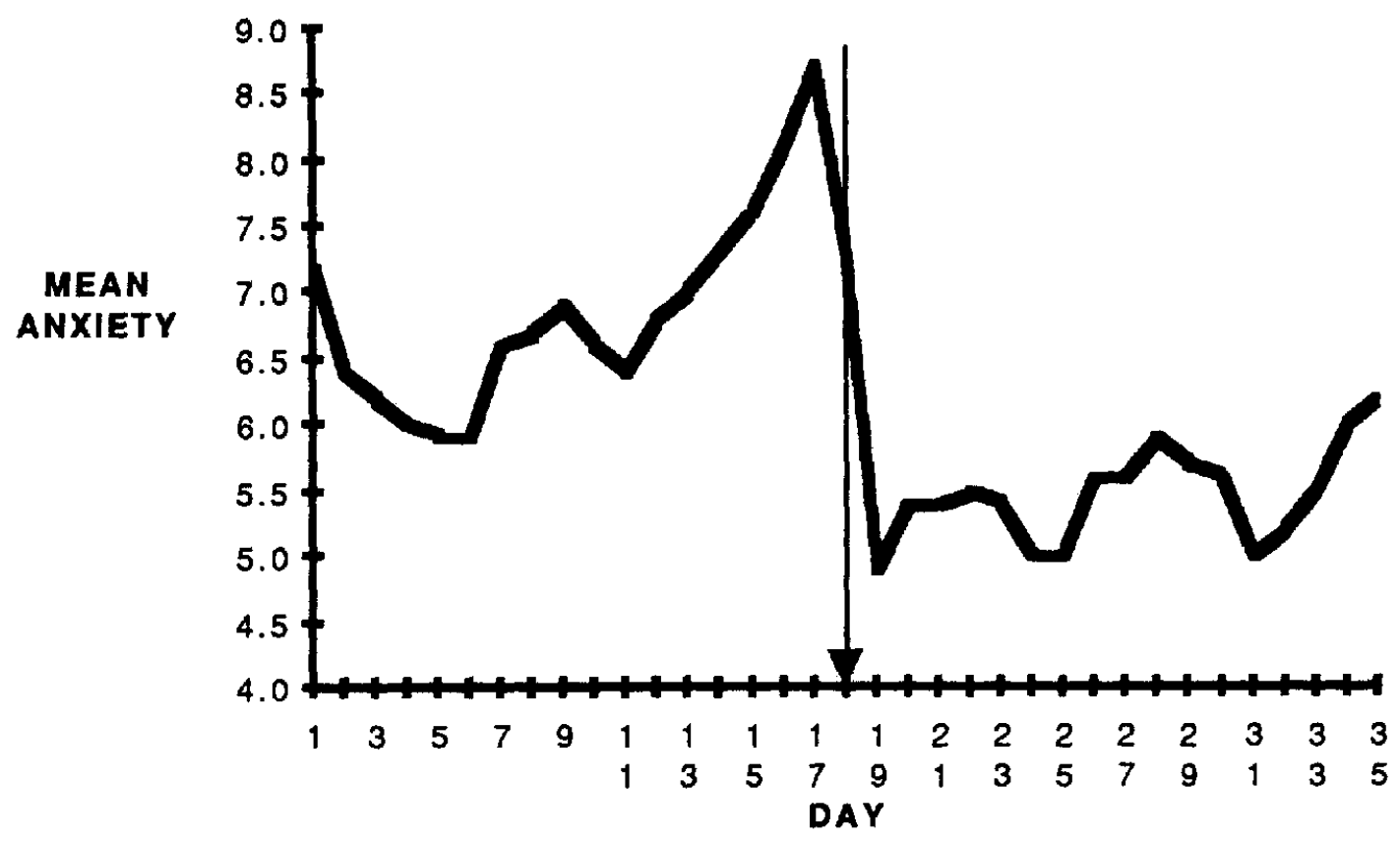

Figure 4. Changes in anxiety over time. (Arrow indicates examination day.) 
Table 3

Intercorrelations of Summed Time 1 and Time 2 Coping Scales, Neuroticism, GPA, Anxiety, and Examination Score

\begin{tabular}{|c|c|c|c|c|c|c|c|c|c|c|}
\hline Variable & 2 & 3 & 4 & 5 & 6 & 7 & 8 & 9 & 10 & 11 \\
\hline 1. Neuroticism & .23 & -.05 & -.04 & .10 & $.29^{*}$ & $.58^{* * *}$ & $.44^{* * * *}$ & $.32^{*}$ & $.43^{* *}$ & .05 \\
\hline 2. GPA & - & -.12 & -.21 & -.08 & .19 & .09 & .10 & .08 & .08 & $.60^{* * *}$ \\
\hline 3. Problem-focused coping & & - & $.34 *$ & $.39^{* * *}$ & -.19 & -.10 & -.05 & .08 & .22 & -.14 \\
\hline 4. Focus on the positive & & & - & .26 & .12 & .01 & -.18 & -.16 & -.12 & .16 \\
\hline 5. Seek support & & & & - & -.09 & .05 & .09 & -.13 & -.02 & .03 \\
\hline 6. Distancing & & & & & - & $.42^{* *}$ & .27 & .16 & .00 & .16 \\
\hline 7. Wishful thinking & & & & & & - & $.68^{* * * * *}$ & $.36^{* *}$ & $.53^{* * * *}$ & .05 \\
\hline 8. Self-blame & & & & & & & - & .23 & $.42^{* *}$ & -.05 \\
\hline 9. Initial anxiety & & & & & & & & - & $.61^{* * *}$ & .03 \\
\hline 10. Proximal anxiety & & & & & & & & & - & -.09 \\
\hline 11. Examination score & & & & & & & & & & - \\
\hline
\end{tabular}

Note. All coefficients are based on an $N$ of 53 except those involving examination score, where the $N$ is 48 . GPA $=$ grade point average.

${ }^{*} p<.05 .^{* *} p<.01 .^{* * *} p<.001$.

examination. Therefore, I defined proximal (or final) anxiety as the mean level over the 4 days before the examination (Days 14-17). Anxiety change is defined as the difference between the measures of initial and proximal anxiety.

Neuroticism was significantly related to anxiety change in the week immediately preceding the examination. In a regression analysis that controlled for initial anxiety and GPA, neuroticism (in its continuous form) predicted change in anxiety between its initial and proximal levels. ${ }^{2}$ The standardized coefficient (beta) was .26, $t(49)=2.3, p<.05 .{ }^{3} \mathrm{GPA}$ was controlled to determine the effects of neuroticism on anxiety for students with equivalent records of academic success. The next step was to test whether coping explained the relationship between neuroticism and anxiety increases.

Does coping mediate the link between neuroticism and increased anxiety? Before testing the relationship among neuroticism, coping, and anxiety change, I first averaged, for each coping scale, the two measures obtained before the examination (i.e., at T1 and T2). Neuroticism-coping relationships were similar at these time points (as seen in Table 1). The resulting scores were used to index coping efforts during the preexamination period.

Table 3 presents Pearson correlations among these coping measures, neuroticism, GPA, initial and proximal anxiety, and examination score. Note that wishful thinking and self-blame correlate as high as their reliabilities, $r(53)=.68, p<.001$. As will be shown, this degree of collinearity posed problems for identifying specific coping mediators of the neuroticism-anxiety relationship.

Figure 5 presents the results of a path analysis showing how coping mediated the relationship between neuroticism and anxiety change. Using a series of multiple regression analyses, the neuroticism-anxiety relationship can be divided into two parts, a part mediated through coping (the indirect effect of neuroticism on anxiety change) and a part unrelated to coping (the direct effect of neuroticism on anxiety change). To demonstrate that coping mediates the neuroticism-anxiety relationship, the indirect effect must be relatively large.

The direct and indirect effects of neuroticism on anxiety change were obtained as follows (see Cohen \& Cohen, 1983, chap. 9). All six coping scales were added to the basic regression model relating neuroticism to proximal anxiety, controlling for initial anxiety and for GPA. The beta for neuroticism fell from .26 to $.12 .^{4}$ The latter coefficient is the direct effect of neuroticism on anxiety change, and it is nonsignificant, $t(43)=0.99$, $n s$. The indirect effect of neuroticism through coping is, therefore, $.26-.12=.14$ units, showing that the set of coping variables explained just over half $(54 \%)$ of the neuroticism-anxiety relationship.

How much did each coping scale uniquely contribute to this indirect effect? The unique indirect effect of neuroticism through a given coping scale is the product of (a) the partial relationship between neuroticism and that coping scale and (b) the partial relationship between that coping scale and anxiety change.

The neuroticism-to-coping relationships are shown in Figure 5 by the betas linking neuroticism to each coping scale (the coefficients above the left-hand set of arrows). Wishful thinking

\footnotetext{
${ }^{2}$ Because the regression model predicts proximal anxiety, controlling for initial anxiety, the dependent measure is algebraically identical to change in anxiety, controlling for initial level (i.e., residualized change in anxiety) (see Dwyer, 1983, or Kessler \& Greenberg, 1981, for a discussion of this type of regression model).

${ }^{3}$ Other things being equal, one would expect the aggregation of several days' anxiety measures to increase the reliability of the total score over the individual measures. However, the correlations between neuroticism and daily anxiety on each of the 4 days before the examination differed only slightly from the correlation between neuroticism and the total proximal anxiety score. A possible reason for this pattern of results is that the daily measures were already highly reliable $(\alpha=.87)$ multi-item composites. These results suggest that any differences in the correlations between the two measures of anxiety (initial and proximal) and other variables (e.g., neuroticism and coping) are not due to differences in reliability.

4 To legitimately perform this analysis, it is necessary to assume that neuroticism does not interact with coping to predict anxiety. Prior to performing the analysis, this assumption was tested by adding terms indexing the six coping scales and the six Neuroticism $\times$ Coping interactions to the original an xiety-change equation. None of the individual Neuroticism $\times$ Coping interactions were significant, nor did the set of interactions contribute significantly to explaining variance in anxiety change.
} 
35 Days Before

Exam.
35 Days Before and 10 Days Before Exam.
Final Week

Before Exam.

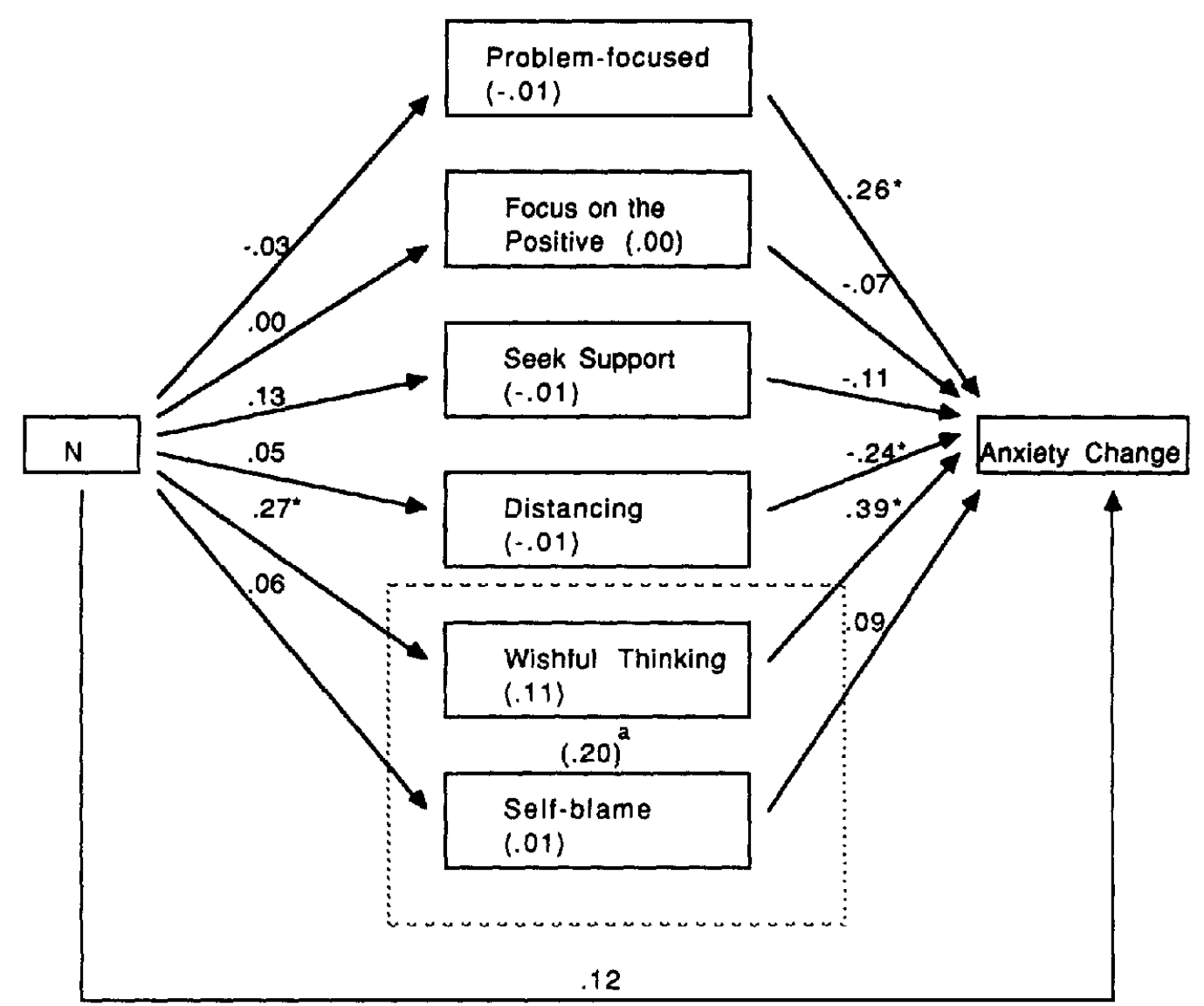

Figure 5. Relationship among neuroticism (N), coping, and subsequent anxiety change: standardized regression coefficients $(N=53)$. (Arrows from $N$ to each coping scale indicate standardized partial regression coefficients [betas], net of the other coping scales, and grade point average. Numbers in parentheses are the mediational effect of each coping scale, obtained by multiplying each $\mathrm{N}$-to-coping beta by its corresponding coping-to-anxiety beta. Mediational effect through both wishful thinking and selfblame.

${ }^{*} p<.05$.)

is the only scale that has a significant independent relationship to neuroticism: $\beta=.27, t(44)=2.47, p<.05$. These betas were obtained by regressing each coping variable on neuroticism, controlling for the other coping variables, GPA, and initial anxiety.

The coping-to-anxiety relationships are shown in Figure 5 by the betas linking each coping scale to anxiety change (the coeffcients above the right-hand set of arrows). Here it can be seen that three coping modes have unique effects on anxiety. The more students engaged in wishful thinking at $\mathrm{T} 1$ and $\mathrm{T} 2$, the more their anxiety increased in the week following $T 2, \beta=.39$, $t(43)=2.44, p<.05$. The more they engaged in distancing, the less their anxiety increased, $\beta=-.24, t(43)=-2.15, p<.05$. Finally, the more they engaged in problem-focused coping, the more their anxiety increased, $\beta=.26, t(43)=2.29, p<.05$.

Multiplying each neuroticism-to-coping beta by its corre- sponding coping-to-anxiety beta provides the unique indirect effect of neuroticism through each coping scale. These products are the numbers in parentheses beneath the titles of each coping scale in Figure 5. Only wishful thinking plays a substantial unique mediational role, accounting for .11 units of the neuroticism-anxiety relationship; all other effects are close to zero.

As noted earlier, however, wishful thinking and self-blame correlate as high as their reliabilities, suggesting that they should not be treated as separate variables. Thus, I assessed their combined mediational effect. As shown in Figure 5 by the number in parentheses at the center of the dashed box, the combined effect is large, .20 units. Although self-blame had a unique effect of only .01 units, because it was so highly correlated with wishful thinking, it shared with it a .08 -unit mediational effect $(.20-.01-.11=.08$ units). 
If wishful thinking and self-blame are treated as a unit, the sum of the unique indirect effects of all the coping scales is -.01 (problem-focused) +.00 (focus on positive) -.01 (seek support $)-.01$ (distancing) +.20 (wishful thinking/self-blame $)=$ .17 units. This is larger than the total indirect effect of .14 units (discussed above). The discrepancy occurs because of joint indirect effects due to correlations between two or more coping scales (as for wishful thinking and self-blame above). The sum of the joint indirect effects is, however, very small: $(14-.17)=$ -.03 units.

These results show, therefore, that wishful thinking and selfblame were the principal coping responses through which neuroticism led to increases in distress. Interestingly (as shown in the repeated-measures analysis), these were the coping responses whose relationship to neuroticism emerged only under stress.

\section{Neuroticism, Coping, and Examination Score}

I hypothesized that neuroticism would be unrelated to examination performance because of a compensatory coping process whereby performance-impeding coping responses would be counteracted by performance-enhancing coping responses.

Neuroticism and ipsatized examination score. Consistent with previous research, neuroticism was unrelated to ipsatized performance under stress. In a regression analysis controlling for GPA, neuroticism did not predict examination score, $\beta=$ $-.07, t(41)=-0.57, n s$. This dependent measure-MCAT score controlling for past GPA-shows whether students performed better or worse than their prior performance would predict. Presumably, subjects deviated from their predicted performance because they used effective or ineffective coping efforts in the intervening period. The distribution of ipsatized examination scores was approximately normal (the Shapiro-Wilk $W$ was .99 , a highly probable value, $p>.90$, for normally distributed data).

Do compensatory coping processes explain why neuroticism is unrelated to examination performance? To assess the mediational effect of coping on ipsatized examination score, I added the six coping scales to the MCAT score regression model. The neuroticism effect changed from -.07 to -.09 (the latter coefficient is nonsignificant, $t(40)=-0.55, n s)$. The total indirect effect through coping, then, is $(-.07)-(-.09)=.02$ units.

The compensation hypothesis implies that this small indirect effect should result from two mediational effects of opposite sign: a negative effect through wishful thinking and selfblame (coping mechanisms that lead to increases in anxiety) and a positive effect through one or more coping scales that reflect compensatory efforts (distancing and problem-focused coping).

No such pattern emerged. Although neuroticism predicted distancing, wishful thinking, and self-blame (shown earlier), neither these nor any of the other coping scales showed any unique relationship to ipsatized examination score. Thus, none of the coping scales mediated the neuroticism-performance relationship.

\section{Discussion}

\section{Neuroticism and Increases in Anxiety}

As predicted by the state-trait theory of anxiety, neuroticism was associated with increases in anxiety under stress. Although previous studies have found that the association between neuroticism and anxiety is greatest under stress, these studies did not adjust for preexisting anxiety differences (Watson \& Clark, 1984). By predicting anxiety change scores and controlling for initial level of anxiety, the present study overcomes this limitation and confirms that neuroticism indexes emotional vulnerability to stress.

\section{Coping as a Mediator of the Neuroticism-Anxiety Relationship}

Confirmation of the mediational hypothesis. Ineffective coping modes, specifically wishful thinking and self-blame, explained-or mediated-over half the effect of neuroticism on anxiety. These results contradict McCrae and Costa's (1986) conclusion that coping plays no causal role in generating psychological distress. Rather, the results suggest that neuroticism leads people to cope ineffectively, and this coping, in turn, leads to increases in distress. ${ }^{5}$

As noted in the introduction, there is reason to believe that McCrae and Costa's (1986) study did not provide a strong test of the mediational model of coping. Because McCrae and Costa asked subjects to recall how they had coped with a target event that had occurred up to 21 months previously, it is possible that their subjects' reports were inaccurate. Perhaps because subjects could not accurately recall the target situation, they may have reported how they typically coped with stress, thereby confounding coping with personality. It is, of course, unclear whether these biases operated in the McCrae and Costa study. Thus, given the conflict between the results of the present study and that of McCrae and Costa, further tests of the neuroticismcoping-distress relationship are clearly called for.

Coping and the state-trait theory of anxiety. The relationships among neuroticism, coping, and anxiety found here suggest that coping has an interactional component that is consistent with the state-trait theory of anxiety. Neuroticism was related to wishful thinking and self-blame only under conditions of stress, and these coping modes, in turn, lead to the anxiety increases under stress predicted by the state-trait theory (Endler \& Edwards, 1982; Eysenck \& Eysenck, 1985; Spielberger et al., 1970).

Such results confirm the importance of temporal factors in the study of personality and coping. Interactional perspectives on personality predict that personality effects will emerge only

\footnotetext{
${ }^{5}$ The analyses reported above examined the effects of coping, controlling for neuroticism. However, in the McCrae and Costa article (1986) that demonstrated that the coping-distress relationship was spurious, both extraversion and neuroticism were controlled. To test whether the coping-distress relationship might be an artifact of extraversion, the mediational analyses were rerun, controlling for both extraversion and neuroticism. In these analyses, the direct effects of coping on anxiety remained virtually unchanged.
} 
at certain times in a coping process. Thus, one must use research designs that are sensitive to this phenomenon, that are longitudinal, and that obtain measurements at theoretically relevant time points.

Neuroticism, distancing, and anxiety. Not all coping scales, however, showed the Neuroticism $\times$ Time interactions found for wishful thinking and self-blame. For example, neuroticism predicted the use of distancing both before and after the MCAT examination. One explanation for this result is that distancing is a generalized mode of coping used by those high in neuroticism to lower their chronically high levels of anxiety (Figure 5 shows that distancing leads to decreases in anxiety). Previous research indicates that neuroticism leads to distress even in the absence of stressful events (Watson \& Clark, 1984; see Bolger \& Schilling, in press, for an empirical illustration). Perhaps persons high in neuroticism are continually preoccupied with lowering this distress. Distancing may be the principal mode of coping they use to achieve this end. ${ }^{6}$

\section{Other Coping Results}

Several other coping results warrant discussion. First, it has been shown that the anxiety-exacerbating effects of wishful thinking and self-blame were almost indistinguishable. Although factor analyses of the Ways of Coping Scale have shown wishful thinking and self-blame to be separate coping dimensions (Marshall \& Dunkel-Schetter, 1987), these scales overlapped substantially in the present study. They were intercorrelated as high as their respective reliabilities; their patterns of change over time were almost identical; and their mediation of the neuroticism-anxiety relationship had a large shared component. Previous studies have already documented that wishful thinking and self-blame are associated with poor mental health under stress (e.g., Felton et al, 1984; Folkman \& Lazarus, 1985). It appears from the present study that these ruminative, self-deprecating thoughts go hand in hand and that they are important determinants of increases in anxiety, at least during a major academic stressor.

Second, it is somewhat puzzling that problem-focused coping apparently leads to increases in anxiety. Although the use of problem-focused coping before an important examination is, arguably, an adaptive coping strategy, this strategy appears to have had costs for subjects' mental health. Is it possible that this result is spurious because of unmeasured heterogeneity in the experience of the MCAT? Although the MCAT is objectively the same for all students, some have higher GPAs than others, and this heterogeneity may lead less-well-prepared students to simultaneously engage in more problem-focused coping and to be more anxious. If this heterogeneity were not taken into account, a spurious relationship could be found between problem-focused coping and anxiety. Because variability in GPA was controlled in all analyses, however, this explanation seems unlikely.

Perhaps problem-focused coping does indeed lead to increases in anxiety. The need to prepare for a crucial examination may unavoidably increase one's awareness of the threatening event and one's sense of anxiety. Given that rival interpretations based on heterogeneity in the stressful event and the sample can be ruled out, this latter interpretation seems the most reasonable one.

Finally, although the focus of this article was on personality determinants of coping, the situational effects observed earlier were striking. For all coping scales, the proportion of variance in coping due to time of measurement was far larger than that due to neuroticism or the Neuroticism $\times$ Time interaction. Although this finding can be attributed, in part, to the design of the study, whereby subjects were followed through various phases of a major stressful event, it is nonetheless remarkable how situationally directed coping proved to be. As such, these results confirm previous theory and research on the importance of situational determinants of coping (Lazarus \& Folkman, 1984; Mattlin, Wethington, \& Kessler, 1990; McCrae, 1984).

\section{Neuroticism, Coping, and Examination Performance}

As hypothesized, neuroticism did not influence examination performance. Compensatory coping processes, whereby the increased use of effective coping modes counteracted the influence of wishful thinking and self-blame, did not explain this finding. Rather, none of the coping modes affected examination performance. Failure to predict performance outcomes may reflect the idiosyncrasies of the stressor or the measurement intervals used in this study. Perhaps if coping had been measured closer in time to the examination (I obtained the T2 coping measure 10 days prior), a compensatory balance between effective and ineffective coping efforts might have emerged.

Alternatively, conventional measures of coping may not, in fact, predict performance under stress. It is noteworthy that two other studies also show that coping can explain distress but not performance. In a study of examination stress, Krantz (1983) found that examination-related coping behaviors (e.g., studying and going to review sessions) did not affect performance. Similarly, in a study of coping with chronic stress at Three Mile Island, Collins, Baum, and Singer (1983) found that scores on the Ways of Coping Scale were poor predictors of performance on a proofreading task and an embedded figures task.

It could be argued that general-purpose inventories such as the Ways of Coping Scale do not predict performance because the coping modes they assess are irrelevant to performance. Yet Krantz (1983) used specific, examination-relevant coping measures. Thus, there is evidence that both general and specific coping measures are, at best, weak predictors of performance under stress. Because of the importance of understanding how stress affects performance (e.g., in the educational and occupational fields), this issue deserves further investigation.

\section{Limitations of the Study}

This study has several important limitations. First, the sample size was small. Certain effects may not have emerged because of low statistical power. Also, the small sample size pre-

\footnotetext{
${ }^{6}$ Distancing did not mediate the neuroticism effect in the path analysis because this analysis controls for initial anxiety, which presumably captures the time-constant effect of neuroticism on distancing.
} 
cluded the testing of more realistic structural equation models than the one presented above.

A further limitation stems from the study's specificity: I examined a specific stressor, an examination, and a specific population, premedical students. Unlike many naturalistic stressors, examinations are well-defined, anticipated, and time-limited events. People's responses to examinations differ correspondingly from responses to other stressors. For example, psychological distress declined rather than increased following the event (see Figure 4). It is unclear, therefore, whether the results will generalize to other stressful events or other populations. Nonetheless, it is important that theories relating personality, coping, and outcomes be subjected to stringent empirical tests. Studying a medical school entrance examination provides greater methodological leverage than that found in previous attempts to test theories of personality and coping. ${ }^{7}$ Whether these findings apply more broadly remains an open question.

Finally, by focusing on people who had already been selected into a stressful situation, this study was unable to examine how personality leads people into stressful situations in the first place. Other research has shown that neuroticism is associated with increased distress not only because of greater reactivity to stressors, but also because of greater exposure to stressors (Bolger \& Schilling, in press). Bolger and Schilling, however, found that exposure to daily stressors is only half as important as reactivity to daily stressors in explaining how neuroticism leads to distress in daily life. By focusing on the coping mechanisms that underlie reactivity to a major stressful event, the current study helps elucidate this key aspect of neuroticism in action.

\section{Conclusions}

In summary, this study has shown that neuroticism emerges in patterns of coping with a major stressful event and that certain coping modes, namely wishful thinking and self-blame, help explain why neuroticism leads to increases in anxiety under stress. None of the coping modes, however, explained the relationship between neuroticism and performance under stress. Although neuroticism predicted coping, coping did not predict performance-a disturbing finding, but one that is consistent with other studies.

By identifying a major stressful event in the lives of premedical students and by using an intensive, prospective measurement strategy, this study has demonstrated that personality (i.e., neuroticism) influences the coping strategies people select and that these coping strategies influence subsequent outcomes (i.e., changes in emotional distress). This contributes to the understanding of how static personality traits reveal themselves dynamically under stress.

\footnotetext{
${ }^{7}$ There exists a large research literature on the topic of test anxiety. Unlike the approach taken here, this literature treats examination stress as a focus of study in itself, rather than as an empirical illustration of more general processes of stress and coping. A major source book for this work is Sarason (1980).

\section{References}

Baum, A., Grunberg, N. E., \& Singer, J. E. (1982). The use of psychological and neuroendocrinological measurements in the study of stress. Health Psychology, 1, 217-236.
}

Bock, R. D. (1975). Multivariate statistical methods in behavioral research. New York: McGraw-Hill.

Bolger, N. (1987). The manifestation of personality and social resources in coping with a major stressful event. Unpublished doctoral dissertation, Cornell University, Ithaca, NY.

Bolger, N., \& Schilling, E. A. (in press). Personality and the problems of everyday life: The role of neuroticism in exposure and reactivity to daily stress. Journal of Personality.

Cantor, N., Norem, J. K., Niedenthal, P. M. Langston, C. A, \& Brower, A. M. (1987). Life tasks, self-concept ideals, and cognitive strategies in a life-transition. Journal of Personality and Social Psychology, 53. 1178-1191.

Cohen, J., \& Cohen, P. (1983). Applied multiple regression/correlation analysis for the behavioral sciences (2nd ed.). Hillsdale, NJ: Erlbaum.

Collins, D. L., Baum, A , \& Singer, J. (1983). Coping with chronic stress at Three Mile Island: Psychological and biochemical evidence. Health Psychology, 2, 149-166.

Costa, P. T., \& McCrae, R. R. (1985). The NEO Personality Inventory manual. Odessa, FL: Psychological Assessment Resources.

Dwyer, J. H. (1983). Statistical models for the social and behavioral sciences. New York: Oxford University Press.

Endler, N. S., \& Edwards, J. (1982). Stress and personality. In L. Goldberger \& S. Breznitz (Eds.), Handbook of stress: Theoretical and clinical aspects (pp. 36-48). New York: Free Press.

Eysenck, H. J., \& Eysenck, M. W. (1985). Personality and individual differences. New York: Plenum Press.

Eysenck, H. J., \& Eysenck, S. B. G. (1964). Manual of the Eysenck Personality Inventory. San Diego, CA: Educational and Industrial Testing Service.

Eysenck, M. W. (1983). Anxiety and individual differences. In G. R. J. Hockey (Ed.), Stress and fatigue in human performance (pp. 273298). New York: Wiley.

Felton, B. J., \& Revenson, T. A. (1984). Coping with chronic illness: A study of illness controllability and the influence of coping strategies on psychological adjustment. Journal of Consulting and Clinical Psychology, 52, 343-353.

Felton, B. J., Revenson, T. A., \& Hinrichsen, G. A. (1984). Stress and coping in the explanation of psychological adjustment among chronically ill adults. Social Science and Medicine, 18, 889-898.

Fleischman, J. A. (1984). Personality characteristics and coping patterns. Journal of Health and Social Behavior, 25, 229-244.

Folkman, S., \& Lazarus, R, S. (1980). An analysis of coping in a middleaged community sample. Journal of Health and Social Behavior, 21, 219-239.

Folkman, S., \& Lazarus, R. S. (1985). If it changes it must be a process: Study of emotion and coping during three stages of a college examination. Journal of Personality and Social Psychology, 48, 150-170.

Holohan, C. J., \& Moos, R. H. (1987). Personal and contextual determinants of coping strategies. Journal of Personality and Social Psychology, 52, 946-955.

Kessler, R. C., \& Greenberg, D. (1981). Linear panel analysis: Models of quantitative change. New York: Academic Press.

Kessler, R. C., Price, R. H., \& Wortman, C. B. (1985). Social factors in psychopathology: Stress, social support, and coping processes. $A n$ nual Review of Psychology, 36, 351-372.

Krantz, S. E. (1983). Cognitive appraisals and problem-directed coping: A prospective study of stress. Journal of Personality and Social Psychology, 44, 638-643.

Lazarus, R. S., \& Folkman, S. (1984). Stress, appraisal, and coping. New York: Springer.

Lorr, M., \& McNair, D. M. (1971). The Profile of Mood States manual. San Diego, CA: Educational and Industrial Testing Service.

Marshall, G., \& Dunkel-Schetter, C. (1987, September). Conceptual and methodological issues in the study of coping: Dimensionality of cop- 
ing. Paper presented at the 95th annual convention of the American Psychological Association, New York.

Mattlin, J., Wethington, E., \& Kessler, R. C. (1990). Situational determinants of coping and coping effectiveness. Journal of Health and Social Behavior, 31, 103-122.

McCrae, R. R. (1984). Situational determinants of coping responses: Loss, threat, and challenge. Journal of Personality and Social Psychology, 46, 919-928.

McCrae, R. R., \& Costa, P. T. (1986). Personality, coping, and coping effectiveness in an adult sample. Journal of Personality, 54, 385-405.

Mechanic, D. (1962). Students under stress: A studyin the social psychology of adaptation. New York: Free Press.

Moore, B. S., Sherrod, D. R., Liv, T. J., \& Underwood, B. (1979). The dispositional shift in attribution over time. Journal of Experimental Social Psychology, 15, 553-569.

Norem, J. K., \& Cantor, N. (1986a). Anticipatory and post hoc cushioning strategies: Optimism and defensive pessimism in "risky" situations. Cognitive Therapy and Research, J0, 347-356.

Norem, J. K., \& Cantor, N. (1986b). Defensive pessimism: "Harnessing" anxiety as motivation. Journal of Personality and Social Psychology, 51, 1208-1217.

Parkes, K. R. (1984). Locus of control, cognitive appraisal, and coping in stressful episodes. Journal of Personality and Social Psychology, $46,655-668$.

Parkes, K. R. (1986). Coping in stressful episodes: The role of individ- ual differences, environmental factors, and situational characteristics. Journal of Personality and Social Psychology, 51, 1277-1292.

Pearlin, L. I., Lieberman, M. A., Menaghan, E. G, \& Mullan, J. T. (1981). The stress process. Journal of Health and Social Behavior, 22, 337-356.

Peterson, C. (1980). Memory and the "dispositional shift." Social Psychology Quarterly, 43, 372-380.

Rosenthal, R., \& Rosnow, R. L. (1985), Contrast analysis: Focused comparisons in the analysis of variance. New York: Cambridge University Press.

Sarason, 1. G. (1980). Test anxiety: Theory, research and applications. Hillsdale, NJ: Erlbaum.

Scheier, M. F., Weintraub, J. K., \& Carver, C. S. (1986). Coping with stress: Divergent strategies of optimists and pessimists. Journal of Personality and Social Psychology, 51, 1257-1264.

Spielberger, C. D., Gorsuch, R. L, \& Lushene, R. E. (1970). Manual for the State-Trait Anxiety Inventory. Palo Alto, CA: Consulting Psychologists Press.

Watson, D., \& Clark, L. A. (1984). Negative affectivity: The disposition to experience negative emotional states. Psychological Bulletin, 96 , $465-490$.

Received July 28,1988

Revision received June 30, 1989 Accepted February 21,1990

\title{
Sternberg Appointed Editor of Psychological Bulletin, 1991-1996
}

The Publications and Communications Board of the American Psychological Association announces the appointment of Robert J. Sternberg, Yale University, as editor of Psychological Bulletin for a 6-year term beginning in 1991. Beginning immediately, manuscripts should be directed to

\author{
Robert J. Sternberg \\ Yale University \\ Department of Psychology \\ P.O. Box 11 A Yale Station \\ New Haven, Connecticut 06520-7447
}

